\title{
Cyanide-insensitive Respiration in Acanthamoeba castellanii. Changes in Sensitivity of Whole Cell Respiration during Exponential Growth
}

\author{
By STEVEN W. EDWARDS AND DAVID LLOYD \\ Department of Microbiology, University College, Newport Road, Cardiff CF2 ITA
}

(Received 4 July 1977)

\begin{abstract}
Respiration of Acanthamoeba castellanii shows varying sensitivity to cyanide during exponential growth in a medium containing proteose peptone, glucose and yeast extract. After $20 \mathrm{~h}$ growth, respiration was stimulated up to $40 \%$ by I mM-cyanide; sensitivity to cyanide then gradually increased until $90 \%$ inhibition of respiration was attained in lateexponential phase cultures. Salicyl hydroxamic acid alone never stimulated or inhibited respiration by more than $20 \%$ but, when added together with cyanide, inhibition was always 70 to $100 \%$ from $3 \mathrm{~h}$ onward. Sensitivity to antimycin A was similar, but not identical to that shown to cyanide; when antimycin A was added together with salicyl hydroxamic acid, the inhibition was greater. Increased sensitivities to arsenite and malonate were also observed in late-exponential phase cultures. These changes in sensitivities were not associated with alterations in the growth medium since similar changes in sensitivity to inhibitors were observed during growth in conditioned medium. A rotenone-sensitive site is associated with cyanide-stimulated respiration and the results suggest that $A$. castellanii possesses a branched electron transport system.
\end{abstract}

\section{INTRODUCTION}

Previous work on the mitochondrial respiratory chain of the soil amoeba Acanthamoeba castellanii revealed the presence of $b, c$ and $a$-type cytochromes (Lloyd \& Griffiths, 1968; Edwards et al., 1977). Lloyd \& Griffiths (1968) showed that oxidation of NAD+-linked substrates by mitochondria isolated from exponentially dividing cultures proceeds via a rotenone and piericidin A-insensitive pathway which they assumed to involve only two sites of oxidative phosphorylation. A later report (Evans, 1973) confirmed this finding but showed that mitochondria from stationary phase cultures possessed rotenone sensitivity and energy conservation at site I. Spectral evidence suggests the presence of two cyanide-reacting components in purified mitochondria of $A$. castellanii and there are also a number of unidentified CO-reacting oxidases which participate in the light-reversal of CO-inhibition of respiration in late-exponential phase whole cells (Edwards et al., 1977).

For the initial $30 \mathrm{~h}$ of exponential growth of $A$. castellanii, glucose is not utilized, respiration rates are low and adenylate charge values are less than $0 \cdot \mathrm{I}$, mainly due to the production of large amounts of AMP, much of which is found extracellularly (Edwards \& Lloyd, 1977). These features are not observed when organisms are grown in conditioned medium, suggesting that there is a change in the growth medium which is completed by $30 \mathrm{~h}$.

We now report the effect of specific inhibitors of mitochondrial electron transport on whole cell respiration of $A$. castellanii. 


\section{METHODS}

Growth and maintenance of the organism. Cultures of Acanthamoeba castellanii were maintained and grown as described previously (Edwards et al., 1977) with shaking at $30^{\circ} \mathrm{C}$ in a medium containing (\%,w/v): Difco proteose peptone, 0.75 ; Oxoid yeast extract, 0.75 ; glucose, 1.5 . Organisms were counted in a FuchsRosenthal haemocytometer slide (Baird \& Tatlock, Chadwell Heath, Romford, Essex) after suitable dilution in either fresh growth medium or $50 \mathrm{~mm}-\mathrm{MgCl}_{2}$. Cultures were inoculated with mid-exponential phase organisms to give an initial population of approx. $10^{5}$ organisms $\mathrm{ml}^{-1}$. Conditioned medium was obtained by removing cells from a $48 \mathrm{~h}$ culture by centrifugation at $3000 \mathrm{rev} . \mathrm{min}^{-1}$ for $\mathrm{I} \cdot 5 \mathrm{~min}$ in the $6 \times 250 \mathrm{ml}$ head of an MSE 18 centrifuge. The supernatant was then autoclaved and inoculated as above.

Measurements of oxygen uptake. Oxygen uptake rates were measured polarographically with a Clark electrode as described previously (Lloyd \& Brookman, 1967). Measurements were made on I or $2 \mathrm{ml}$ (depending on cell density) of undiluted suspensions of cells in growth medium. Antimycin A, rotenone and salicyl hydroxamic acid (SHAM) were used as ethanolic solutions and additions were made so that the final ethanol concentration was not more than $0.5 \%(\mathrm{v} / \mathrm{v})$. This concentration alone caused $2 \%$ inhibition of respiration. Potassium cyanide, sodium arsenite and sodium malonate, all at $\mathrm{pH} 7 \cdot 4$, were used as aqueous solutions.

Chemicals. SHAM was from Koch-Light, rotenone from Sigma, and antimycin A from Boehringer. All other chemicals were of analytical grade.

\section{RESULTS}

\section{Sensitivity of early- and late-exponential phase organisms to respiratory inhibitors}

Preliminary experiments revealed marked variations in the sensitivity of whole cell respiration to cyanide at different times during exponential growth. Cyanide and SHAM added together always resulted in a greater inhibition than that produced with either inhibitor alone. In early-exponential phase cultures, respiration was stimulated by up to $40 \%$ by cyanide at concentrations up to $2.5 \mathrm{~mm}$, but the effect of sequential additions of cyanide was variable and the extent of stimulation did not increase with increasing amounts of cyanide to a plateau value (Fig. I $a$ ). This phenomenon was found consistently with this inhibitor only at this particular phase of growth. In the presence of I mM-SHAM (which itself stimulated respiration by $5 \%$ ) a plateau was reached at about $80 \%$ inhibition within the range 0.05 to $0.2 \mathrm{~mm}$-cyanide; at higher concentrations the inhibition increased and was complete by $0.7 \mathrm{~mm}$ (Fig. I $a$ ). In late-exponential phase cultures, however, cyanide alone had a much greater inhibitory effect on respiration with $85 \%$ inhibition at a concentration $0.3 \mathrm{mM}$. Again, in the presence of I mM-SHAM, inhibition by cyanide was greater $(100 \%$ at $0.8 \mathrm{~mm}$ ) and a biphasic effect was evident (Fig. I $b$ ). Sensitivity of whole cell respiration to antimycin $\mathrm{A}$ appeared to be similar but not identical to sensitivity to cyanide. Respiration in early-exponential phase cultures was only inhibited at very high concentrations [50 $\mu \mathrm{mol}$ antimycin A ( $10^{6}$ organisms) $)^{-1}$ ] while late-exponential phase cultures were inhibited by $60 \%$ at $3 \mu \mathrm{mol}\left(\right.$ (10 $^{6}$ organisms) ${ }^{-1}$ (Fig. I $c, d$ ). In both types of cultures, inhibition was more complete in the presence of I mM-SHAM. SHAM alone never inhibited respiration by more than $20 \%$ at the concentrations tested in either type of culture, but it was effective if antimycin A or cyanide were added before the addition of SHAM (Fig. I $e, f$ ). Increased sensitivities to arsenite and malonate were also evident in late-exponential phase cultures (Table $\mathrm{r}$ ).

\section{Changes in sensitivity to SHAM and.cyanide during exponential growth}

Cell numbers increased exponentially with a doubling time of $8.5 \mathrm{~h}$ until a stationary population was reached after $65 \mathrm{~h}$. Oxygen uptake rates increased exponentially and doubled over I I. $5 \mathrm{~h}$ for the initial $25 \mathrm{~h}$, after which time the rate of increase of respiration doubled every $8 \mathrm{~h}$ (Fig. $2 \mathrm{a}$ ). Addition of I mM-cyanide initially inhibited respiration by $50 \%$ but this effect was rapidly lost and respiration was progressively more stimulated (Fig. 2c). After $20 \mathrm{~h}$ growth, respiration was stimulated by $40 \%$, but it then became increasingly sensitive to cyanide until the maximum inhibitory effect $(90 \%)$ was observed at 

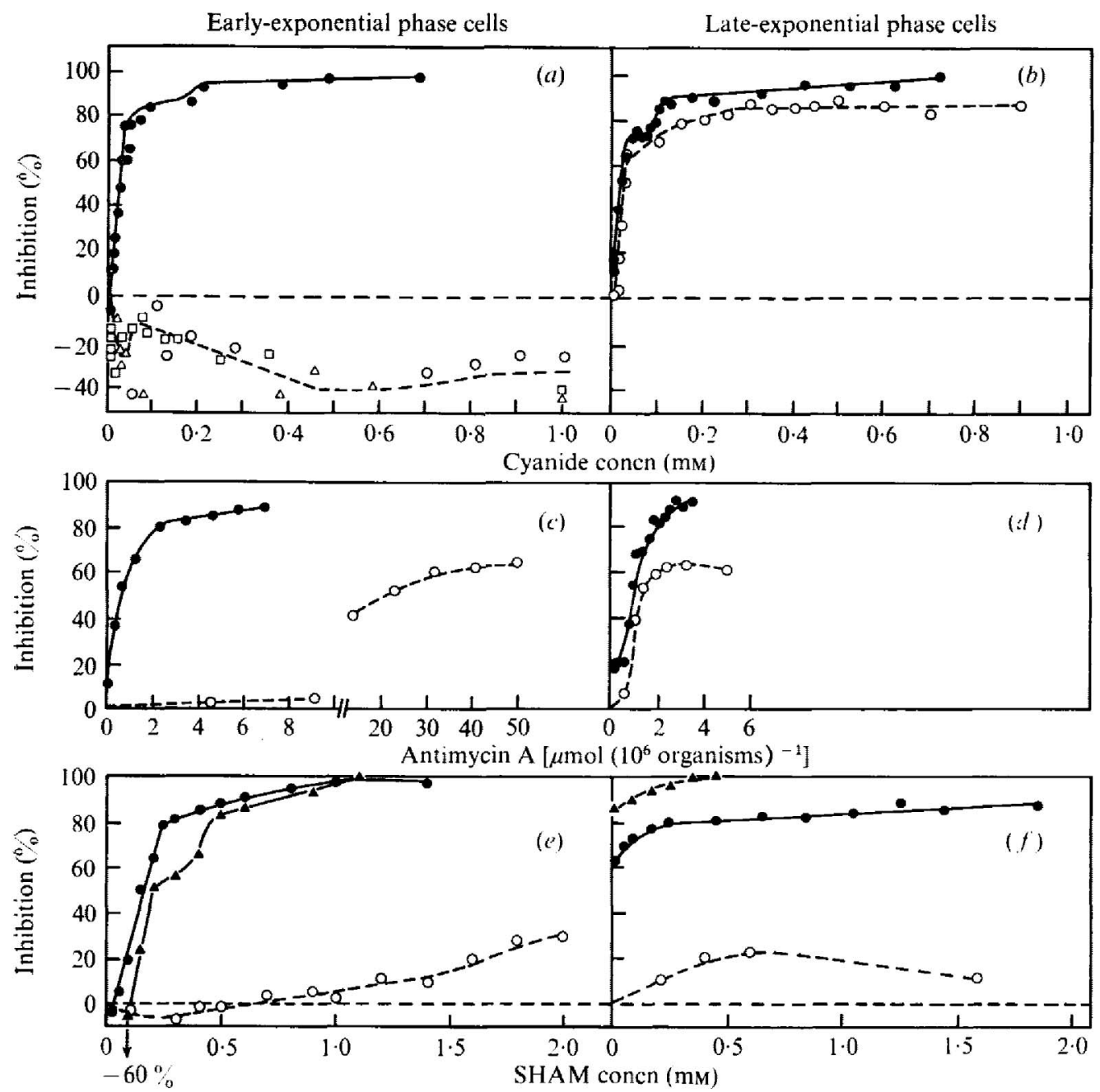

Fig. 1. Variations in the effect of inhibitors of respiration on early- and late-exponential phase cultures of A. castellanii. Inhibition (or stimulation, -) of respiration (\%) is expressed as function of inhibitor titre, the control $(0 \%)$ being the respiration rate in the absence of any inhibitor. $(a, c, e)$ Cells from early-exponential phase cultures, $3.5 \times 10^{5}$ to $5 \times 10^{5}$ organisms $\mathrm{ml}^{-1} ;(b, d, f)$ cells from late-exponential phase cultures, $3 \times 10^{6}$ to $5 \times 10^{6}$ organisms $\mathrm{ml}^{-1} \cdot(a, b)$ Effect of cyanide alone $(O, \square, \triangle$, three experiments) or in the presence of I mM-SHAM $(\bullet) .(c, d)$ Effect of antimycin A alone $(0)$ or in the presence of I mM-SHAM $(0) .(e, f)$ Effect of SHAM alone $(O)$ or in the presence of I mM-cyanide $(\Delta)$ or antimycin $A$ at a concentration of $6 \mu \mathrm{mol}\left(10^{6} \text { organisms) }\right)^{-1}(\bullet)$.

the beginning of the stationary phase. Addition of I mM-SHAM alone never inhibited or stimulated respiration by more than $20 \%$ after the first $3 \mathrm{~h}$ (Fig. $2 b$ ) but, together with I mM-cyanide, inhibition was almost complete. Respiration was inhibited initially by $50 \%$ in the presence of both inhibitors and sensitivity increased during exponential growth so that, after $20 \mathrm{~h}$, inhibition was always $80 \%$ or greater. There was no apparent difference in sensitivity of respiration when the order of addition of SHAM and cyanide was reversed. 


\section{Table I. Effect of malonate, arsenite and rotenone on the respiration of early-and late-exponential phase cultures of A. castellanii}

Titration curves for each inhibitor were obtained by adding small portions of inhibitor to the reaction vessel. $I_{50}$ values are the concentrations of an inhibitor causing $50 \%$ of the maximum inhibition of respiration caused by that inhibitor. These are typical results of four experiments, all of which gave similar results.

\begin{tabular}{|c|c|c|c|c|c|c|}
\hline \multirow[b]{2}{*}{ Inhibitor } & \multicolumn{3}{|c|}{$\begin{array}{l}\text { Early-exponential phase cells } \\
\left(4 \times 10^{5} \text { organisms } \mathrm{ml}^{-1}\right)\end{array}$} & \multicolumn{3}{|c|}{$\begin{array}{l}\text { Late-exponential phase cells } \\
\left(3.5 \times 10^{6} \text { organisms } \mathrm{ml}^{-1}\right)\end{array}$} \\
\hline & $\begin{array}{c}\text { Maximum } \\
\text { inhibition } \\
(\%)\end{array}$ & $\begin{array}{l}\text { Concn } \\
(\mathrm{mM})\end{array}$ & $\begin{array}{l}\mathrm{I}_{50} \\
(\mathrm{mM})\end{array}$ & $\begin{array}{c}\text { Maximum } \\
\text { inhibition } \\
(\%)\end{array}$ & $\begin{array}{l}\text { Concn } \\
(\mathrm{mm})\end{array}$ & $\begin{array}{c}\mathbf{I}_{50} \\
(\mathrm{mM})\end{array}$ \\
\hline Malonate & I I & 75 & 40 & 60 & 75 & 14 \\
\hline Arsenite & 30 & IO & $3 \cdot 6$ & 70 & 10 & $2 \cdot 5$ \\
\hline Rotenone & 2 & 0.04 & - & 10 & 0.05 & 0.01 \\
\hline
\end{tabular}

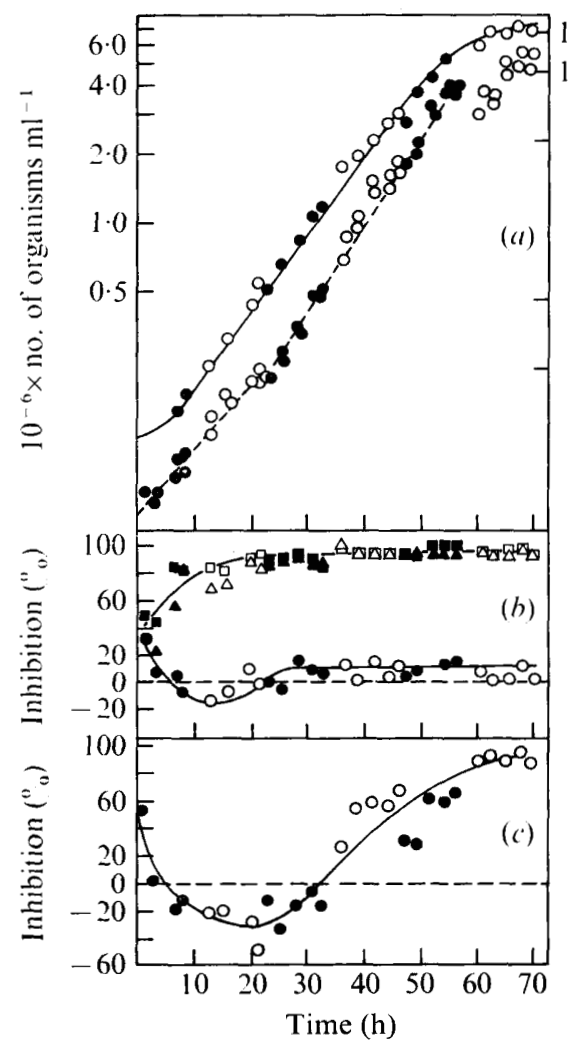

Fig. 2

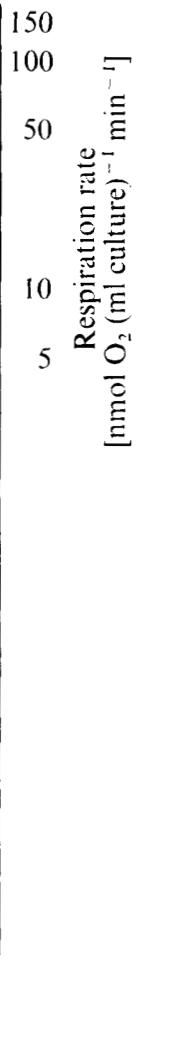

Fig. 2. Changes in sensitivity of whole cell respiration of $A$. castellanii to cyanide and SHAM during exponential growth. Open and closed symbols are results from two separate experiments. (a) Cell density ( - ) and oxygen uptake rates (-- ). (b) Inhibition of respiration produced by SHAM $(O, O)$, SHAM plus cyanide $(\triangle, \Delta)$ and cyanide plus $\operatorname{SHAM}(\square, \square)$. (c) Effect of cyanide on respiration. The concentrations of inhibitors were $1 \mathrm{~mm}$ and inhibition is expressed as a percentage of the respiration rate in the absence of any inhibitor.

Fig. 3. Changes in sensitivity of whole cell respiration of $A$. castellanii to cyanide and SHAM during exponential growth in conditioned medium. Cells were inoculated into medium that had previously supported growth for $48 \mathrm{~h}$. Symbols as in Fig. 2. 
Table 2. Effect of rotenone on cyanide-stimulated respiration of $A$. castellanii

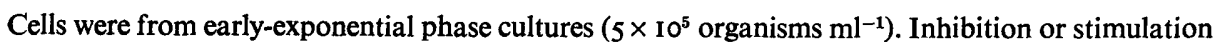
of respiration is expressed as a percentage of the control rate. These are typical results of six experiments which all gave similar results.

\begin{tabular}{|c|c|c|}
\hline & $\begin{array}{l}\text { Oxygen uptake } \\
\text { rate } \\
{\left[\text { nmol min }^{-1}\right.} \\
\text { (10 }^{6}{\text { organisms })^{-1} \text { ] }}^{2}\end{array}$ & $\begin{array}{c}\text { Inhibition or } \\
\text { stimulation }(-) \\
(\%)\end{array}$ \\
\hline $\begin{array}{l}\text { Control } \\
+ \text { I mM-cyanide } \\
+ \text { I } 2 \mu \mathrm{M} \text {-rotenone }\end{array}$ & $\begin{array}{r}7.75 \\
10.45 \\
6.81\end{array}$ & $\begin{array}{r}-34 \cdot 8 \\
12 \cdot I\end{array}$ \\
\hline $\begin{array}{l}\text { Control } \\
+ \text { I } 2 \mu_{\mathrm{M}-\text {-rotenone }} \\
\text { + I mM-cyanide }\end{array}$ & $\begin{array}{l}7 \cdot 7 \\
7 \cdot 7 \\
7 \cdot 89\end{array}$ & $\begin{array}{c}0 \\
-2.4\end{array}$ \\
\hline
\end{tabular}

\section{Changes in sensitivity to SHAM and cyanide during exponential growth in conditioned medium}

Exponential growth (mean generation time $9 \mathrm{~h}$ ) occurred until $47 \mathrm{~h}$ when the generation time increased to $18.5 \mathrm{~h}$, and a stationary phase population of $6.8 \times 10^{6}$ organisms $\mathrm{ml}^{-1}$ was reached after $75 \mathrm{~h}$ (Fig. $3 \mathrm{a}$ ). The rate of increase of oxygen uptake rates closely paralleled cell numbers. The sensitivity of respiration to cyanide (Fig. 3 c) was similar (although not identical) to that shown in Fig. $2(c)$, with $48 \%$ stimulation at about $15 \mathrm{~h}$. From 30 to $47 \mathrm{~h}$ cyanide had no effect but inhibition then increased to a maximum of about $80 \%$ by $70 \mathrm{~h}$. The effects of SHAM alone and cyanide plus SHAM (Fig. $3 b$ ) appeared similar to those shown in Fig. $2(b)$.

\section{Effect of rotenone on cyanide-stimulated respiration}

Rotenone alone had little effect on whole cell respiration of late- or early-exponential phase cultures (Table I). However its effect on respiration in the presence of cyanide was examined in an attempt to explain cyanide-stimulation of respiration in early-exponential phase cultures (Table 2). When I mM-cyanide was added to a cell suspension containing rotenone no cyanide-stimulated respiration was observed. The effect of rotenone on cyanidestimulated respiration was to reduce the stimulated rate to that obtained without inhibitor, i.e. the stimulatory effect of cyanide was cancelled.

\section{DISCUSSION}

Cyanide-insensitive respiration has been reported in a wide variety of eukaryotic microorganisms (Lloyd, 1974; Henry \& Nyns, 1975; Knowles, 1976). Cyanide-stimulated respiration, on the other hand, has only been found in relatively few organisms and the mechanism has not been extensively investigated. Resistance of whole cell respiration to specific inhibitors of mitochondrial electron transport may not be entirely surprising since many non-mitochondrial pathways may participate. However, substituted hydroxamic acids (e.g. SHAM) have been shown in almost every example tested to specifically inhibit mitochondrial, cyanide-insensitive respiration, as demonstrated originally by Schonbaum et al. (1971) in plant mitochondria. The role of this alternative, SHAM-sensitive oxidase is not fully understood but it appears to function when the existing pathway has been impaired: the alternative oxidase in Neurospora crassa is elaborated in respiratory mutants or by growth under those conditions where the mitochondrial cytochrome chain is impaired or diminished (see Lloyd, 1974). In A. castellanii, while there are variations in the ratios of individual cytochromes during exponential growth, there is no change in the nature of these components until late in the stationary phase when the degradative mechanisms of encystment may have begun (Edwards \& Lloyd, I977). The initial $30 \mathrm{~h}$ of exponential growth are unusual in that 


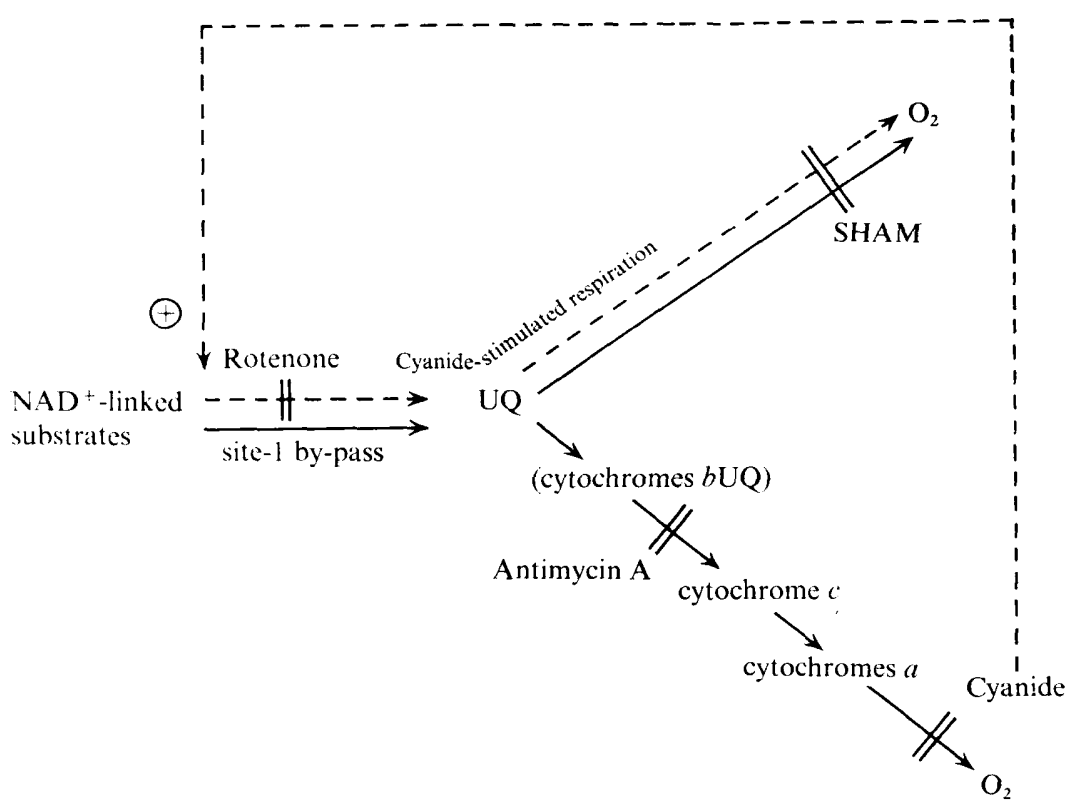

Fig. 4. Pathways of electron transport in A. castellanii. The scheme is based on results presented in this paper and from Edwards et al. (1977). The branch point accommodates the ubiq uinone (UQ) cycle, originally proposed by Mitchell (1975) and modified by Rich \& Moore (1976) for the alternative pathway of plant mitochondria.

oxygen uptake rates are low, glucose is not utilized and adenylate charge values are extremely low due to the production of a large pool of AMP, much of which is found extracellularly (Edwards \& Lloyd, 1977). These features are not observed in conditioned medium suggesting that they are dependent on the growth medium, which is changed by $30 \mathrm{~h}$. Clearly, cyanide-insensitive respiration is not associated with these features or with changes in the growth medium since a similar overall pattern of sensitivity to cyanide is still observed in conditioned medium. What therefore initiates these changes in sensitivities to inhibitors is unclear and requires further study. Also of interest is the finding that the occurrence of the alternative oxidase has no appreciable effect on ATP levels (Edwards \& Lloyd, 1977) and that the cells are still able to grow at their maximum rate.

The results presented suggest there is a branched electron transport system in $A$. castellanii, as shown in Fig. 4, which is similar to that suggested for $N$. crassa and some higher plants (Lambowitz \& Slayman, I97I ; Bahr \& Bonner, 1973). Whether the differences observed in early- and late-exponential phase cultures are due to the progressive loss of the alternative oxidase or to alteration of the controlling parameters at the branch-point is uncertain.

The finding that rotenone has little effect on the respiration of exponentially dividing cells is in agreement with previous reports when $A$. castellanii was grown in mycological peptone (Lloyd \& Griffiths, I968; Evans, 1973). The absence of sensitivity to rotenone in exponential phase cultures has been suggested as indicating the absence of site I, which is, however, present in stationary phase cultures where more efficient energy conservation is required (Evans, 1973). A similar acquisition of sensitivity to rotenone (or piericidin A) and ability to demonstrate site I accompanying the transition to stationary phase, was found in Candida utilis (Katz, I97I ; Katz, Kilpatrick \& Chance, 197I; Ohnishi, 1972), but this has been shown to reflect a by-pass mechanism of site I which operates when cells are growing under optimal conditions (Ohnishi, 1972). This by-pass does not function when cells are growing under sub-optimal conditions, or during stationary phase. It would appear that a similar by-pass mechanism of site I may operate in $A$. castellanii; this by-pass is not 
functional in the presence of cyanide. Thus the stimulation of respiration by cyanide may be partially explained as representing an increased electron flux through the rotenone sensitive site. While the elucidation of these pathways in whole cells is complicated by the nature of the growth medium, further information should be gained with work on isolated mitochondria.

The work was carried out during the tenure of a Medical Research Council Studentship (S.W.E.).

\section{REFERENCES}

BAHR, J. T. \& BonNer, JR., W. D. (1973). Cyanideinsensitive respiration. II. Control of the alternative pathway. Journal of Biological Chemistry 248, 3446-3450.

EDwards, S. W. \& LloYd, D. (1977). Changes in oxygen uptake rates, enzyme activities, cytochrome amounts and adenine nucleotide pool levels during growth of Acanthamoeba castellanii in batch culture. Journal of General Microbiology 102, I 35-144.

Edwards, S. W., Chagla, A. H., Griffiths, A. J. \& LlOYD, D. (1977). The cytochromes of Acanthamoeba castellanii. Biochemical Journal (in the Press).

Evans, D. A. (1973). Growth phase and the number of phosphorylation sites in the mitochondrial electron transport chain of Acanthamoeba castellanii. Journal of Protozoology 20, 336-338.

HenRY, M. F. \& Nyns, E. J. (1975). Cyanideinsensitive respiration. An alternative mitochondrial pathway. Sub-cellular Biochemistry 4, I-65.

KATZ, R. (197I). Growth phase and rotenone sensitivity in Torulopsis utilis: difference between exponential and stationary phase. FEBS Letters 12, 153-156.

Katz, R., Kilpatrick, L. \& Chance, B. (197I). Acquisition and loss of rotenone sensitivity in Torulopsis utilis. European Journal of Biochemistry 21, 30I-307.
KNowles, C. J. (1976). Microorganisms and cyanide Bacteriological Reviews 40, 652-680.

Lambowitz, A. M. \& Slayman, C. W. (197I). Cyanide-resistant respiration in Neurospora crassa. Journal of Bacteriology 108, 1087-1096.

LLOYD, D. (1974). Mitochondria of Microorganisms. London and New York: Academic Press.

Lloyd, D. \& Brookman, J. S. G. (1967). An oxygen electrode vessel. Biotechnology and Bioengineering 9, $27 \mathrm{I}-272$.

LlOYD, D. \& GRIfFiths, A. J. (I968). The isolation of mitochondria from the amoeba Hartmannella castellanii Neff. Experimental Cell Research 5r, 29I-300.

Mrtchell, P. (1975). The protonmotive $Q$ cycle: a general formulation. FEBS Letters 59, 137-1 39.

OHNISHI, T. (1972). Factors controlling the occurrence of site I phosphorylation in C. utilis mitochondria. FEBS Letters 24, 305-309.

RICH, P. R. \& MOORE, A. L. (1976). The involvement of the protonmotive ubiquinone cycle in the respiratory chain of higher plants and its relation to the branchpoint of the alternative pathway. FEBS Letters 59, 339-343.

Schonbaum, G. R., Bonner, JR, W. D., Storey, B. T. \& BAHR, J. T. (197I). Specific inhibition of the cyanide-insensitive respiratory pathway in plant mitochondria by hydroxamic acids. Plant Physiology 47, 124-128. 